
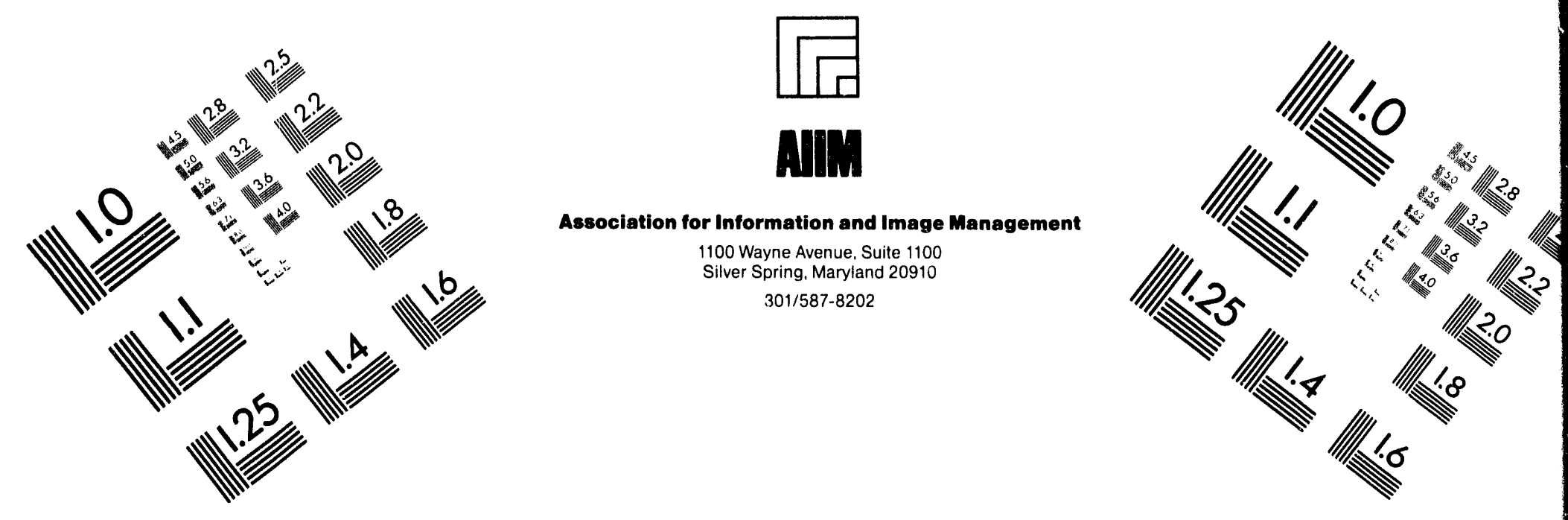

\title{
Centimeter
}

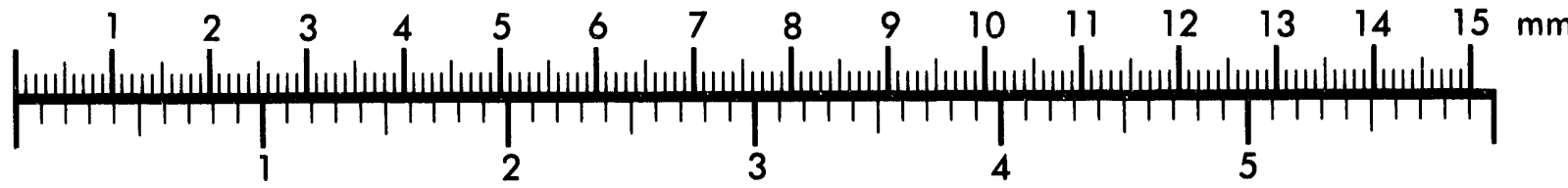

Inches
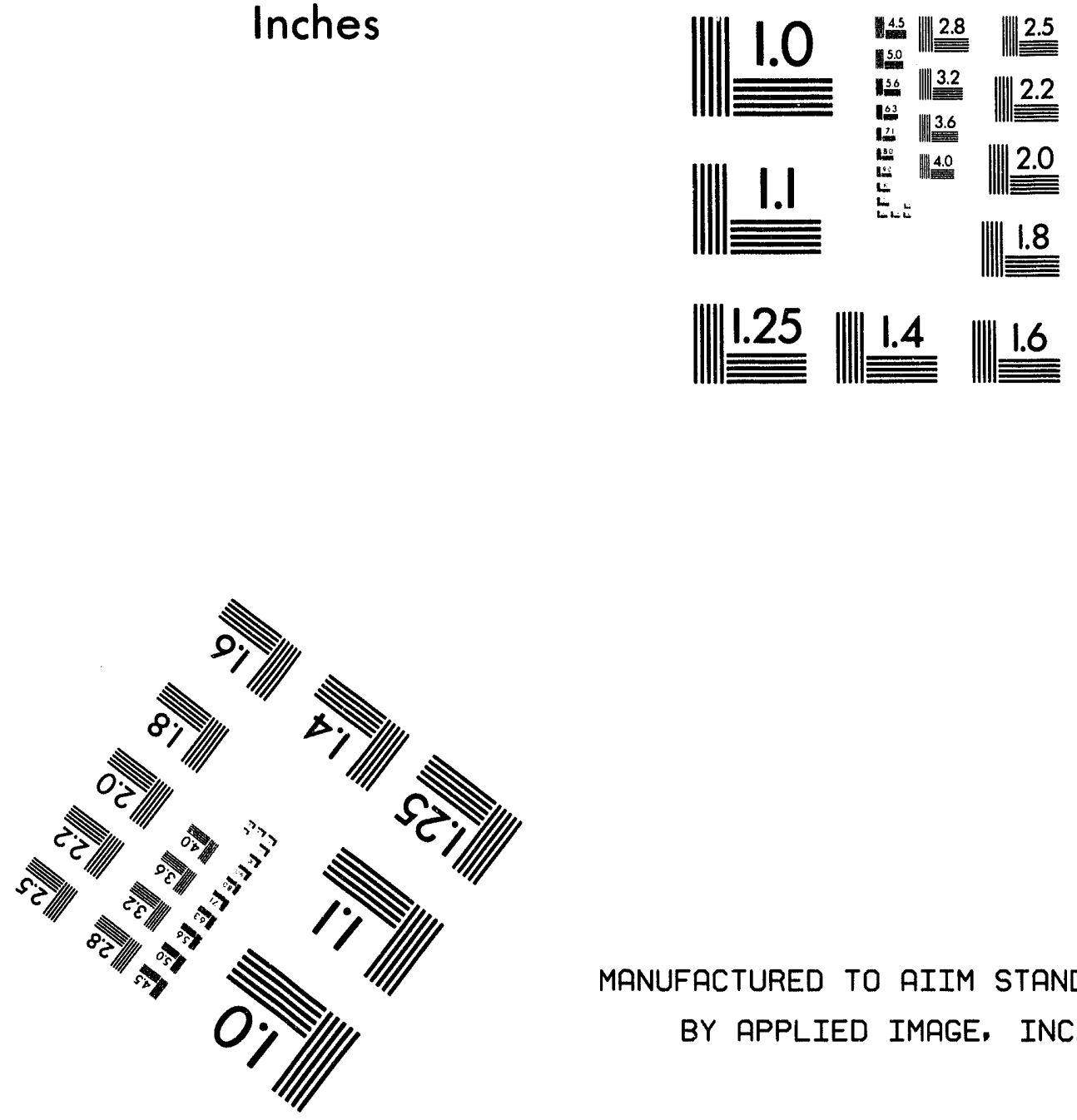

MANUFACTURED TO AIIM STANDARDS

BY APPLIED IMAGE, INC.

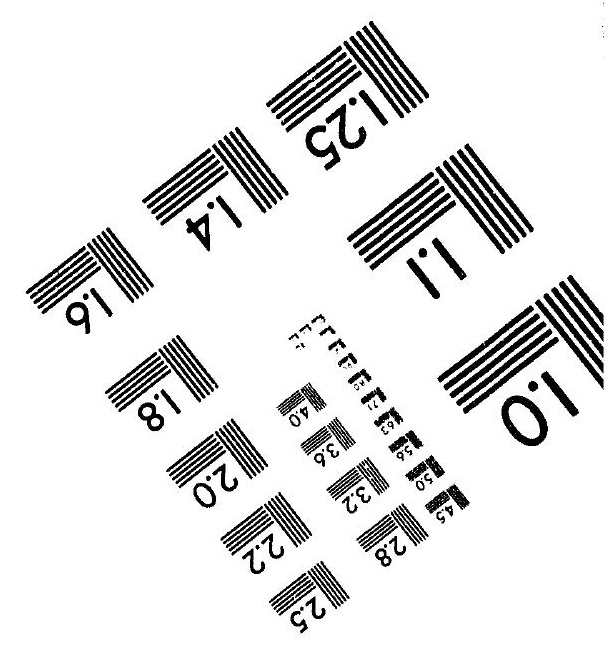



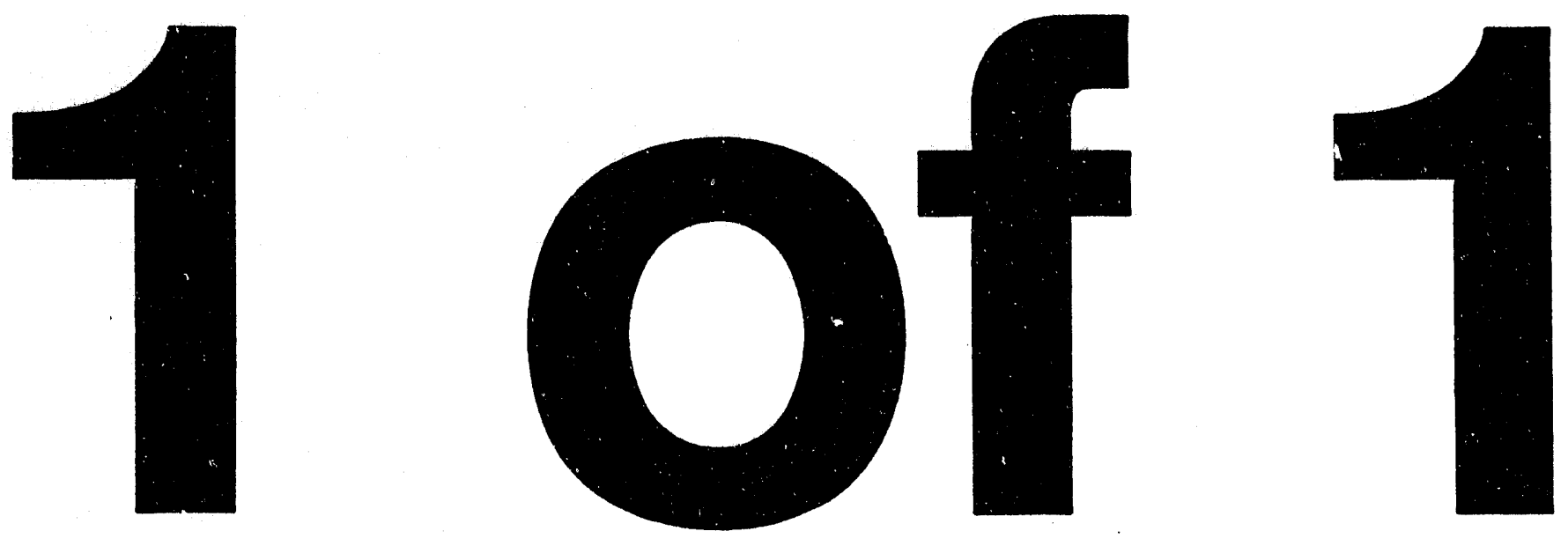


\section{CONF-940892--1 SAND-94-0846C}

\section{Sealing of Boreholes Using Natural, Compatible Materials: Granular Salt}

\section{Ray E. Finley}

YMP Performance Assessment Applications Dept.

Sandia National Laboratories, Albuquerque, NM 87185

\section{David H. Zeuch}

Geomechanics Dept.

Sandia National Laboratories, Albuquerque, NM 87185

John C. Stormont

Environmental Restoration Technologies Dept.

Sandia National Laboratories, Albuquerque, NM. 87185

Jaak J. K. Daemen

Dept. of Mining Engineering,

University of Nevada at Reno, Reno, Nevada

This wook performed at 8 endin National Laboratories supported by the U.S.

Depertmext of Eners under contract DE-AC04-94A185000.

ABSTRACT: Granular salt can be used to construct high performance permanent seals in boreholes which penetrate rock salt formations. These seals are described as seal systems comprised of the host rock, the seal material, and the seal rock interface. The performance of these seal systems is defined by the complex interactions between these seal system components through time. The interactions are largely driven by the creep of the host formation applying boundary stress on the seal forcing consolidation of the granular salt. The permeability of well constructed granular salt seal systems is expected to approach the host rock permeability $\left(<10_{-21}^{-21} \mathrm{~m}^{2}\left(10^{-9}\right.\right.$ darcy)) with time. The immediate permeability of these seals is dependent on the emplaced density. Laboratory test results suggest that careful emplacement techniques could result in immediate seal system permeability on the order of $10^{-16} \mathrm{~m}^{2}$ to $10^{-18} \mathrm{~m}^{2}\left(10^{-4}\right.$ darcy to $10^{-6}$ darcy). The visco-plastic behavior of the host rock coupled with the granular salts ability to "heal" or consolidate make granular salt an ideal sealing material for boreholes whose permanent sealing is required.

\section{INTRODUCTION}

Effective sealing of penetrations (boreholes) in geologic materials is becoming increasingly important as it is recognized that groundwater resources need to be protected from potential contamination. Boreholes are drilled for a myriad of purposes including oil and gas production, water production, monitoring, site characterization, mineral exploration, and waste disposal. These boreholes penetrate all geologic environments and range in depth from very shallow to depths of up to several kilometers. In the undisturbed geologic system, potential contaminants are separated from freshwater aquifers by low permeability aquitards. Improper plugging, sealing, or abandonment of boreholes which penetrate aquitards can allow the borehole to act as a conduit between the contaminated and freshwater regions. The real or perceived failure of these seal systems to isolate contaminants from groundwater supplies can result in costly litigation and remediation, loss of public confidence and support, and destruction of groundwater resources. Borehole seal performance has been recognized as a potential environmental concern by numerous researchers (USEPA, 1987; National Research Council, 1985). at the top of the plug and are intended to assure immediate performance. The nature of the seal system construction (placement across production and freshwater zones) and test techniques (pressure tests at the top of the seal) suggest that this standard practice may not identify seal problems until performance is compromised because the test techniques may only sample a small part of the seal.

Well founded concerns that such conventional cementitious seals will degrade with time or will otherwise be difficult or impossible to demonstrate permanent performance have led workers in radioactive waste disposal programs in the United States and elsewhere to develop new approaches to, and technology for the emplacement of truly permanent seals. Of particular interest here is the approach being taken toward sealing of penetrations in bedded and domal sal formations. Native material (i.e., previously mined-out, granular salt) has been selected as the primary long-term component in these programs, in large part because of its natural compatibility with the host rocks. The experience acquired in evaluating seal materials and systems, necessitated by the requirement to ensure seal integrity and public safety over perhaps thousands of years has led the authors to develon new approaches to sealing boreholes 


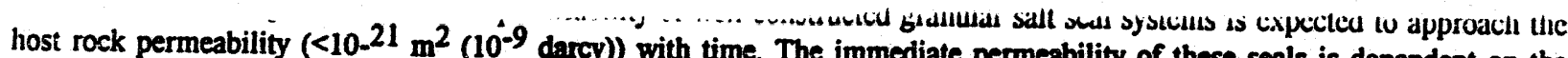
emplaced density. Laboratory test results surgest with time. The immediate permeability of these seals is dependent on the permeability on the order of $10^{-16} \mathrm{~m}^{2}$ to $10^{-18} \mathrm{~m}^{2}\left(10^{-4}\right.$ darcy to $10^{-6}$ darcy $)$ Thes could result in immediate seal system coupled with the granular salts ability to "heal" or $\mathrm{m}^{2}\left(10^{-4}\right.$ darcy to $10^{-6}$ darcy). The visco-plastic behavior of the host rock coupled with the granular salts ability to "heal" or consolidate make granular salt an ideal sealing material for boreholes whose
permanent sealing is required.

\section{INTRODUCTION}

Effective sealing of penetrations (boreholes) in geologic materials is becoming increasingly important as it is recognized that groundwater resources need to be protected from potential contamination. Boreholes are drilled for a myriad of purposes including oil and gas production, water production, monitoring, site characterization, mineral exploration, and waste disposal. These boreholes penetrate all geologic environments and range in depth from very shallow to depths of uy to several kilometers. In the undisturbed geologic system, potential contaminants are separated from freshwater aquifers by low permeability aquitards. Improper plugging, sealing, or abandonment of boreholes which penetrate aquitards can allow the borehole to act as a conduit between the contaminated and freshwater regions. The real or perceived failure of these seal systems to isolate contaminants from groundwater supplies can result in costly litigation and remediation, loss of public confidence and support, and destruction of groundwater resources. Borehole seal performance has been recognized as a potential environmental concern by numerous researchers (USEPA, 1987; National Research Council, 1985).

Typical well abandonment requirements and practice include sealing of any water-producing zones by the use of cements. Open-hole cementing is typically done to plug abandoned wells, to assist in directional or follow-on drilling, to minimize or restrict lost circulation, or for isolation of specific zones in the borehole to restrict water inflow. Secondary pr.ssure grouting may also be used to reduce the permeability of the surrounding hot rock. High density drilling muds are also used in abandonment of oil and gas wells. Typical tests to assure borehole seal quality include a complete review of well construction data as well as Mechanical Integrity Tests (MITs) such as pressure tests of the seal system as a check for cracks and leaks i thecasing and seal/rock interface. These tests are conducted at the top of the plug and are intended to assure immediate performance. The nature of the seal system construction (placement across production and freshwater zones) and test techniques (pressure tests at the top of the seal) suggest that this standard practice may not identify seal problems until performance is compromised because the test techniques may only sample a small part of the seal.

Well founded concerns that such conventional cementitious seals will degrade with time or will otherwise be difficult or impossible to demonstrate permanent performance have led workers in radioactive waste disposal programs in the United States and elsewhere to develop new approaches to, and technology for the emplacement of truly permanent seals. Of particular interest here is the approach being taken toward sealing of penetrations in bedded and domal salt formations. Native material (i.e., previously mined-out, granular salt) has been selected as the primary long-term component in these programs, in large part because of its natural compatibility with the host rocks. The experience acquired in evaluating seal materials and sysiems, necessitated by the requirement to ensure seal integrity and public safety over perhaps thousands of years has led the authors to develop new approaches to sealing boreholes through rock salt.

A fact which appears to have gone unnoticed is that thousands of borcholes penetrate evaporite formations for reasons unrelated to radioactive waste isolation, simply because $25 \%$ of all continental areas are underiain by evaporites (Blatt, et al., 1980). Indeed, evaporite deposits are LIKELY Y to be drilled because they offen act as natural traps for oil and gas. The United States Environmental Protection Agency (USEPA, 1987? estimates that there are 1.2 million oil and gas production wells in the United States alone. In addition, there are uncounted brine reinjection wells used to reinjest oil field brines derive from production activities. Finally, evaporite deposits are actively being used for

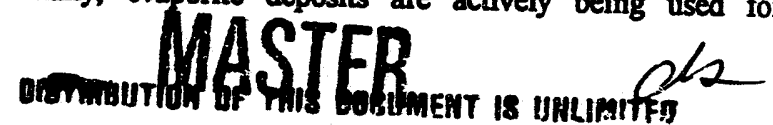


solution-mining and petroleum storage, and are being considered as temporary or terminal storage sites for nonradioactive, hazardous wastes, liquefied natural gas and compressed air. All of these applications have numerous penetrations associated with them, and many of these boreholes will require sealing to satisfy regulatory or opcrational requirements.

Thc approach to sealing now being developed for radioactive waste isolation in salt formations can be readily adapted for PERMANENT sealing of any penetration in an evaporite deposit. Furthermore, it seems likely that with careful thought and planning, the same approach might also bc cimployed in other geologic settings such as shales, chalk and other weak rock. In this paper, we illustrate what must be understood about the seal system and its component materials to make this approach successful, using granular salt as the archetypical example. We first review the concept of a seal system (see Figure 1), which consists not only of the material(s) comprising the "plug" in the penetration, but also the disturbed rock zone (DRZ) bounding the opening, as well as the interface between the plug and the damaged host rock. We will then examine what is known about the properties of intact, "disturbed", and granulated rock salt, (and their expected interactions) that make them attractive candidates for use in seal systems. Next, we touch on aspects of salt behavior that suggest directions for technological developments that might further enhance salt seal system performance immediately upon emplacement. We close with a brief review of the properties that a natural geomaterial should possess to be a good candidate for use in a seal system, and suggest additional materials for study.

The most severe regulatory requirements for seal performance are currently reserved for a few exotic applications such as nuclear waste isolation. Nevertheless, it is inevitable that increasingly stringent performance requirements will also be applied to oil and gas well seals. By sheer weight of rumbers (hundreds of thousands of wells, vs. a handful of radioactive and hazardous waste repositories), emphasis on oil and gas wells may likely have the greatest effect on environmental quality. It is likely that these stricter future requirements will focus on the longevity and demonstrated performance of the borehole seal. Both issues are dealt with under the approach described herein.:

\section{THE SEAL SYSTEM}

Effective design and construction of permanent seals requires an understanding that the problem extends beyond sclection of a long-iived, low permeability plugging material. Penetration of the rock formation introduces mechanical and hydrological changes in the surrounding rock. Left unremediated, this damage to the host rock may provide a long-term or permanent hydrological pathway around the emplaced seal, regardless of its material properties. An understanding of the extent and nature of this damage is therefore necessary if a cost-effective seal is to be designed. In evaporite deposits, at least, it may be possible to parially or completely reverse this damage with proper selection of the sealing material. Alternatively, the problem could be made still worse by selecting a chemically and/or mechanically mismatched sealing material.
There are different plug design options for abandoned wells and penetrations through rock salt and other evaporites depending on the sealing objective. Sealing options include short-term, long-term, and permanent seals. Short-term seals include temporary seals used to effect a change in the downhole condition such as grouting a water-producing zone until a longer-tenn option is required. Long-term seals are considered those seals currently emplaced using conventional equipment and materials. Permanent seals are defined here as seals whose permanence and performance is based on high quality emplacement and chemical compatibility. These permanent seals achieve their performance by emplacing granular natural materials at high density and take advantage of their ability to "heal" over time achieving characteristics similar to the host rock. Here we focus on the concept of PERMANENT SEALS, describe the seal system comprised of the host rock, the seal material, and the seal/rock interface, and discuss some of the important factors that can affect permanent performance

It is suspected that the common practices currently employed for sealing boreholes in rock salt and evaporites do not or cannot satisfy permanence requirements for sealing, especially for hazardous materials. These requirements do recognize the need for chemically compatible seal materials, but use materials such as cements or others whose PERMANENT compatibility cannot easily be demonstrated. An alternative technique is to demonstrate the emplacement of clearly compatible materials such as granular salt for boreholes in rock salt to form a demonstrably (low permeability, high strength, chemically stable) permanent seal. The emplacement of permanent seals will necessarily be composite in design and would include cement bridge plugs on either end to provide confinement for the granular salt as it is emplaced and over longer time periods as the surrounding creeping host rock drives consolidation. Permanent sealing techniques cannot be used in all boreholes. However, this technique can provide an additional tool when permanent sealing of penetrations is required.

This paper focuses on the niechanical and hydrological behavior of seal/rock systems and discusses sealing of boreholes with granular salt. In the following sections we review the knowledge that has been acquired on the hydrologic/mechanical response of the seal/rock system in rock salt, discuss the status of the work in progress, and highlight areas where gaps in our understanding still exist.

We show that there are sound reasons to think that granular salt can be a key component in permanent, rock salt seal systems in boreholes. Furthermore, seal performance and cost-effectiveness are only enhanced by its natural character, a strategy that may find application in other geologic settings, as well.

\section{HOST ROCK PROPERTIES}

The mechanical behavior of rock salt has been studied extensively both in the laboratory and in the field; a complete review is beyond the scope of this paper. For relatively recent reviews, see Wawersik and Zeuch (1986); or Senseney et al. (1993). At low stresses and fast loading

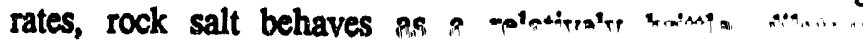


material. At increasing confining stresses, temperatures, and/or slower loading rates, the behavior of rock salt becomes increasingly ductile. At sufficiently great confining stress, temperatures, and/or slow.loading rates, the response of rock salt is perfectly plastic. Rock salt also experiences significant creep, that is, it exhibits time-dependent deformation under sustained deviatoric stresses.

Although there is no universally accepted model of salt creep, there is considerable evidence of the strong dependence of creep on temperature and deviatoric stress. These observations are captured in a simplified model of stcady-state creep, Wawersik and Zeuch, 1986):

$$
\varepsilon=A \sigma^{n} e^{\left(\frac{-a}{R T}\right)}
$$

where,

$\varepsilon=$ Steady-state strain rate

$\mathrm{A}, \mathrm{n}=$ Empirical constants

$\sigma$ - Deviatoric Stress

$Q=$ Activation energy

$\mathrm{R}=$ Universal gas constant

$T=$ Absolute temperature

From this relatively simple relation the following inferences can be drawn regarding the creep of boreholes in rock salt:

- creep increases with depth, due to the increased stress and temperature with depth. Infante and Chenefort (1989) predict that these effects can increase closure in the first hour of drilling from $5 \%$ to $27 \%$ at depths of $3810 \mathrm{~m}$ and $4270 \mathrm{~m}$, respectively.

- as a borehole creeps in on, and transfers load to a seal, the seal will increasingly resist closure, reducing both the deviatoric stress and the creep rate of the surrounding rock.

- the creep rate is very sensitive to the stress term, in particular the stress exponent. Experimentally derived exponents vary from about 2 to 5 (Pfeifle et al, 1983), resulting in closure rates which vary by orders of magnitude (Kelsall and Nelson, 1983).

The drilling of the borehole alters the initial hydrostatic in situ stresses in the region immediately surrounding the borchole. These stress changes produce a fractured, permeability-enhanced disturbed zone around the borehole. The extent of the disturbed zone will naturally vary with depth, host rock material properties, and stress state. However, evidence at the Waste Isolation Pilo; Plant near Carlsbad, New Mexico and elsewhere (e.g., Stormont et al, 1991; Lingle et al., 1982) suggest that the disturbed zone can be roughly described as extending about $1 / 2$ to, 2 borehole radii $(R)$ into the host rock. Figure 2 shows the results of a test to measure the extent of the disturbed zone around a $1-\mathrm{m}$ diameter borehole in rock salt at the WIPP. Monitoring holes were placed at varying radial distances from the as yet uncompleted $1-\mathrm{m}$ borehole. These monitoring holes measured pore pressure changes and permcability before, during, and after completion of the large diameter borehole. The results show a disturbed zone cxtending roughly $1-\mathrm{m}(2 \mathrm{R})$ into the host rock as a consequence of completing the borehole. The figure also shows that the region of significant permeability enhancement extends about $0.5 \mathrm{~m}(1 \mathrm{R})$ from the borehole wall.

These increases in perneability can be up to six orders of magnitude over that of the intact rock salt formation $\left(10^{-21}\right.$ $\mathrm{m}^{2}$ (10-9 darcy)) Stormont et al. (1991). Similarly, Peach (1991) has shown that dilatant volumetric strains under $1 \%$ can increase permeability of natural rock salt by six orders of magnitude.

A number of investigators have shown that fractured rock salt has the capacity to "heal" when subjected to hydrostatic compression comparable to the undisturbed state, with an attendant recovery of the original, low permeability (e.g., Costin and Wawersik, 1981; Sutherland and Cave, 1980; Stormont and Daemen, 1992). The mechanisms of this healing and recovery are not yet understood, but the impact on permeability is clear. Figure 3 from Stormont and Daemen (1992) illustrates the effect of reapplication of hydrostatic stress on samples recovered from a depth of about $650 \mathrm{~m}$ at the WIPP. There is a clear reduction in permeability from the damaged state of roughly $10^{-17} \mathrm{~m}^{2}$ $\left(10^{-5}\right.$ darcy) to the undisturbed permeability of $10^{-21} \mathrm{~m}^{2}$ $\left(10^{-9}\right.$ darcy).

Healing, as manifested by permeability decrease, is clearly shown in the laboratory testing, however, only anecdotal evidence exists for healing occurring in the field. This evidence is presented by Peterson (1987) through two series of gas tracer tests on expansive salt saturated concrete borehole seals. One test was conducted immediately after the concrete was emplaced and cured, the second test was conducted approximately one year later. The tracer gas showed some tracer artival during the first tests, whereas no tracer arrival was seen in the subsequent tests. This suggests that the rock salt surrounding the concrete seal was healed during the one year between the tracer tests.

The importance of both the laboratory and field observations is clear. First, the permeability of even a relatively ductile geomaterial like rock salt can change dramatically (six orders of magnitude) as a consequence of the stress change caused by drilling a borehole. This can have profound impacts on the effectiveness of a seal if the host rock remains damaged. However, the laboratory results also indicate that the DRZ in rock salt can recover its original hydrological properties under certain circumstances, i.e., return to approximately the original stress state. One way to achieve this is to emplace a mechanically compatible "plug" to which load is transferred, and which increasingly supports the closing borehole. The most mechanically compatible material, is of course native rock salt itself. This brings us to a discussion of the advantages of using compacted granular salt as the sealing material.

\section{Seal Materual Characteristics}

Granular rock salt has the potential to be an effective, simple seal material for boreholes which penetrate rock salt formations. Experimental evidence suggests that granular or crushed salt consolidates under certain conditions, resulting in a porosity and permeability that decrease toward values 
comparable to intact salt. For granular sait emplaced in an opening in a rock salt formation, the consolidation is driven by the creep closure of the adjacent host rock which was described previously. Other advantages of granular salt are its availability, low cost, and obvious chemical compatibility with the host rock. Granular salt can be used as a sealing material for those boreholes where the highest performance requirements are a result of either strict regulations or severe consequences for seal system failures.

The time-dependent properties of granular salt have been measured by numerous laboratory researchers. At a given stress, the single most important parameter in the consolidation of granular salt is the presence of a small amount of water. Small amounts of waier accelerate consolidation and the accompanying permeability decreases in comparison with dry granular salt (Zeuch and Holcomb, 1991; Holcomb and Shields, 1987; IT Corp., 1987; Shor et al., 1981; Pfeifle, 1991). The effects of other variables, such as particle size, are secondary and not as obvious.

\section{$!$}

The dependence of salt consolidation on added water can be illustrated by considering the experimental results of Holcomb and co-workers (Holcomb and Hannum, 1982; Holcomb and Shields, 1987). The 1982 tests were conducted on dry (no additional water) granular salt, whereas the 1987 tests involved small amounts ( $<3 \%$ added by weight) of additional water. The volume strain data $\left(d V / d V_{0}\right)$, from both sets of data can be reasonably described by (Holcomb and Hannum, 1982; Holcomb and Shields, 1987):

$$
d V / d V_{0}=a \log (t)+b
$$

where $a$ and $b$ are fitting constants and $t$ is time in seconds. The constant, $b$, is a measure of the initial condition of the sample. To compare times to achieve the same volumetric strain for tests under similar initial and loading conditions, equation (2) can be rewritten as:

$$
t_{1}=t_{2} \frac{a 2}{a l}
$$

The constant, $a$, for wet test data is five to ten times greater than from a comparable dry test. Therefore, for dry granular salt to experience the same strain under similar test conditions requires a time five to ten orders of magnitude greater than that for the wet sample.

Sjaardema and Krieg (1987) developed and implemented a constitutive relationship for the consolidation of granular sall based on the laboratory data of Holcomb and coworkcrs. Numerical calculations of wet granular sait consolidation in WIPP shafts and drifts were then conducted to detcrmine the influence of the presence. of the granular salt on the closure of the shafts and drifts. Up to a fractional density of 0.95 (the extent of the laboratory data the model was based on), the results indicate that no substantial backstress (resistance) develops in the granular salt. That is, the closure is largely unaffected by the presence of granular salt until the porosity in the granular salt was reduced to $5 \%$. This result is not conclusive as a limited number of other laboratory tests on granular salt indicate some bulk modulus increase for compressed granular salt with fractional densities as low as $\mathbf{0 . 8 5}$.

As expected, as consolidation proceeds, the permeability of the granular salt decreases. Figure 4 shows permedability versus fractional density for two tests that proceeded to high fractional densities (low porosities) (Butcher, 1991). In general, permeability values for samples with a fractional density of 0.85 or less are $10^{-15} \mathrm{~m}^{2}\left(10^{-3}\right.$ darcy) or greater values. Between fractional densities of 0.85 and 0.95 , however, the permeability drops dramatically. By 0.95 fractional density, the perneability of the granular salt is on the order of that of intact sait.

Also shown in this figure are data reported from Germany. The higher permeabilities of the German data could be a result of experimental techniques. These data were obtained from liquid permeability tests. Achieving complete saturation of the test fluid with salt is very difficult and channeling enhanced by dissolution is possible. On the other hand, the permeabilities derived from gas measurements could be artificially low due to capillary threshold pressure and relative permeability effects (Butcher, 1991).

The exact mechanism(s) of consolidation of granular salt are not understood. Clearly, water plays an important role. Holcomb and Shields (1987) discuss the possibility of a pressure solution mechanism for consolidation in view of their experimental data, and conclude that further investigation is required. Post-test analyses were conducted on consolidated samples (IT Corp, 1987) and it was again concluded that water played an important role in salt consolidation (and the accompanying permeability decrease) by facilitating pressure solution. irrespective of the details of the mechanism, some form of fluid-phase enhanced deformation is involved (Zeuch, 1990). Zeuch (1990) adapted a model for isostatic hot-pressing to the consolidation of nominally dry gzanular salt, and found good agreement between the model and Holcomb and Hannum's (1982) laboratory data.

While small amounts of water have been determined to benefit consolidation, larger amounts may be detrimental for sealing. It is conceivable that if the granular salt becomes saturated while substantial porosity remains, further consolidation could be impeded by the low compressibility of the entrapped water. Tests by Baes et al. (1983), indicate that water can be readily squeezed out of the salt so as to not impede consolidation even to low permeabilities. The results of Zeuch and Holcomb (1991) indicate that saturated granular salt consolidates similar to granular salt with much less water. However, these laboratory tests have been on drained samples; it is not obvious to what degree water in boreholes could be expelled during consolidation.

The emplacement technique will naturally dictate the initial density of the granular sait in a borehole. The preceding discussion confirms that the careful control over the emplacement process for granular salt is essential to create an effective seal. The current technology for the placement of granular salt seal components is similar to those used for bentonite pellets. These materials can be supplied to the seal location using a dump bailer, air slurry, or simply poured into shallow boreholes. However, these techniques do not provide adequate control over the emplacement process and will result in granular salt seals with a low density and poor quality. The granular materials may have the tendencr in Mhi.m."." :. 
low strength and allowing preferential flowpaths. It is also necessary to emplace these materials with limited water to minimize the buildup of pore pressure during consolidation to low porosities.

Higher emplaced densities will result in a lower permeability and will increase confidence in the permanent performance of the seal. Holcomb and Hannum (1980) found that mercly pouring granular salt into a mold with no added compaction will result in a fractional density of only 0.60 . Compacted granular salt blocks have been prepared with fractional densities of up to 0.85, Finley and Tillerson, 1991; Torres et al., 1992). Recently, the authors have investigated the in situ replacement and compaction of granulated salt. Studies of dynamic compaction techniques suitable for boreholes have been attempted in the laboratory and have resulted in fractional densities approaching 0.90 . These fractional densities correspond to permeabilities of approximately $10^{-17} \mathrm{~m}^{2}\left(10^{-5}\right.$ darcy) based on comparisons with the other laboratory results presented in Figure 4. Field emplacements using these techniques have not yet been attempted.

\section{SEAL SYSTEM PERFORMANCE}

It is of paramount importance to consider the entire seal system when developing and defending designs for sealing boreholes in rock salt. The complex interactions between the seal and the host rock must be recognized so that reasonable predictions of the seal performance can be made. The complicated nature of the in situ system suggests that seals should be designed on a case-by-case basis.

The design of a seal system in rock salt begins with the definition of the performance requirements for the borehole seal system. Short-term, long-term, and permanent seals were defined to represent the range of performance requirements possible for a borehole seal system. Restoring the borehole to a condition comparable to the formation by means of the consolidation of granular salt represents a permanent seal. On the other hand, relying on the performance of a cementitious seal whose properties will eventually degrade is not an optimal approach, even if the degradation is very slow.

The difference in performance of granular salt and cementitious seal systems are given in Figures $5 \mathrm{a}$ and $5 \mathrm{~b}$. Many design considerations are embedded in these figures, and they serve as a useful illustration of the design process. The figures provide the permeability of the seal system as a function of time. In the figures, the values for time are qualitative, and for permeability are approximate. A similar figure could be developed for other sealing materials, notably bentonite. However, bentonite requires structural confinement for it to remain effective and performance is dependent on cementitious seal performance as presented in Figure 5a.

Prior to the drilling of the borehole, the initial permeability of the system is that of the formation. For rock salt, this is a very low value, on the order of $10^{-21} \mathrm{~m}^{2}\left(10^{-9}\right.$ darcy) or less, the permeability increases to that of an open borehole upon drilling. The emplacement of the seal material causes an immediate reduction in the seal system permeability.
The permeability of the cementitious seal system indicates an almost immediate decrease upon seal placement to a value of about $10^{-17} \mathrm{~m}^{2}$ to $10^{-18} \mathrm{~m}^{2}\left(10^{-5}\right.$ to $10^{-6}$ darcy). This permeability is considered the minimum permeability of a carefully constructed cementitious seal system immediately after $\mathrm{pl} \mathrm{l}_{n}$-ement based on experimental evidence of similar systems (Peterson, 1987). The permeability of the seal system can be attributed to the seal/rock interface and the adjacent disturbed rock zone. Creep of the host rock will tend to reduce the permeability of the disturbed rock zone and create a tight seal/rock interface. After some time, the seal system attains its lowest permeability which is equivalent to the permeability of the seal material itself. After some time, cementitious seal materials may begin to degrade because of chemical incompatibility between the seal, the host rock, and the available fluids. Assuming degradation proceeds until the seal is reduced to its individual constituents, the ultimate condition of the seal may be comparable to sand and have a permeability on the order of $10^{-15} \mathrm{~m}^{2}\left(10^{-3} \mathrm{darcy}\right)$. Because the permeability of the cementitious seal system is not expected to achieve a permeability as low as the host rock and the seal may eventually degrade, cementitious seals are considered long. term but not permanent seals by themselves.

The highly time-dependent behavior of a granular salt seal system is illustrated in Figure 5b. For low initial emplacement densities (say 0.8 fractional density), the initial permeability of the seal system is largely a function of the seal material itself. These materials will continue to consolidate as a consequence of the creep closure of the borehole until they achieve a permeability equivalent to the host rock. The time required to achieve this degree of consolidation from an initial fractional density of 0.8 is on the order of hundreds of years for typical creep rates. Higher density initial emplacement of granular salt offers an attractive alternative to cementitious seals. An initial emplaced fractional density of 0.9 can provide immediate performance comparable to the cementitious seals (about $10^{-17} \mathrm{~m}^{2}\left(10^{-5}\right.$ darcy)). As shown in Figure $5 \mathrm{~b}$, higher initial densities would result in even lower immediate permeabilities. The time required for the permeability of initial 0.9 or greater fractional density seals may be less than 100 years. It is important to note that the granular salt seals are not expected to degrade with time owing to the natural compatibility of the seal materials with the host rock. Granular salt seals are therefore considered to be permanent seals.

A design approach which takes advantage of the attributes of both cementitious and granular salt seals is the use of composite seals comprised of both materials. Granular salt components are placed in the substantial rock salt sections. This composite design utilizes the favorable characteristics of both materials and assures high performance throughout the lifetime of the seal. 


\section{DISCLAIMER}

This report was prepared as an account of work sponsored by an agency of the United States Government. Neither the United States Government nor any agency thereof, nor any of their employees, makes any warranty, express or implied, or assumes any legal liability or responsibility for the accuracy, completeness, or usefulness of any information, apparatus, product, or process disclosed, or represents that its use would not infringe privately owned rights. Reference herein to any specific commercial product, process, or service by trade name, trademark, manufacturer, or otherwise does not necessarily constitute or imply its endorsement, recommendation, or favoring by the United States Government or any agency thereof. The views and opinions of authors expressed berein do not necessarily state or reflect those of the United States Government or any agency thereof. 
CONCLUSIONS

A concept of sealing boreholes through rock salt with rock salt has been described in terms of granular salt seals. However, it is reasonable to assume that these concepts can be applied to sealing in other weak rocks which exhibit time-dependent behavior. This behavior can be used to advantage in borehole sealing by using the "driving" energy of the creeping host rock to assist in consolidating the seal material to a very high density thereby creating a seal whose characteristics are not dissimilar to the host rock.

The advantages of in situ compaction of natural materials (as described in this paper for rock salt) for the construction of permanent seals are:

- The permeability of granular salt decreases significantly when the fractional density approaches $90 \%$ to $92 \%$ of the intact density. These are density values approachable using the in situ compaction techniques under development.

- The compaction process in situ can be shown to "lock in" horizontal stress in the compacted material. This horizontal stress enhances the formation of a tight interface and creates a stress condition in the surrounding host rock that accelerates the healing of the disturbed zone that develops during borehole drilling and creep of the surrounding rock.

- In situ compaction techniques using native materials can provide excellent quality control over the emplacement process, thus providing confidence that the seal is consistent in extent and properties throughout.

- The compatibility of the seal material with the surrounding host rock assures that the permanent performance of the seal can be conservatively estimated from the initial emplaced densities. The longterm performance will be enhanced as creep of the surrounding rock reduces the porosity, and hence the permeability of the emplaced seal material to that of the host rock.

\section{REFERENCES}

Baes, C.F., Gilpatrick, L. O., Kitts, F. G., and Shor, A. J. (1983) The Effect of Water in Salt Repositories: Final Report, Oak Ridge National Laboratory Report ORNL-5950, Oak Ridge, TN.

Blatt, H., Middleton, G., and Murray, R. (1980) Origin of Sedimentary Rocks, Prentice-Hall, Englewood Cliffs, New Jersey.

Butcher, B. M. (1991) The Advantages of a Sal/Bentonite Backfill for Waste Isolation Pilot Plant Disposal Rooms, Sandia National Laboratories Report SAND90-3074, Albuquerque, NM.

Costin, L. S., and Wawersik, W. R. (1981) Creep Healing of Fractures in Rock Salt, Sandia National Laboratories Report SAND80-1375, Albuquerque, NM.

Finley, R. E.., and Tillerson, J. R. (1991) WIPP Small-Scale Seal Performance Tests - Status and Impacts. Sandia National Laboratories Report SAND91-2247, Albuquerque, NM

Holcomb, D. J., and Shields, M. (1987) Hydrostatic Creep Consolidation of Crushed Salt With Added Water. Sandia National Laboratories Report SAND87-1990, Albuquerque, NM.

Holcomb, D. J., and Hannum, D. W. (1982) Consolidation of Crushed Salt Under Conditions Appropriate to the WIPP Facility. Sandia National Laboratories Report SAND82-0630, Albuquerque, NM.
Infante, E. F., and Chenevert, M. E. (1989) Stability of Boreholes Drilled Through Salt Formations Displaying Plastic Behavior. SPE Drilling Engineering, Vol. 4, No. 1, March, pp. 57-65.

International Technology Corp. (1987) Laboratory

Investigation of Crushed Salt Consolidation and

Fracture Healing. Office of Nuclear waste isolation Report BMU/ONWI-631.

Keisall, P.C., and Nelson, J. W. (1983) Geologic and

Engineering Characteristics of Gulf Region Salt Domes Applied to Underground Storage and Mining. Sixth International Symposium on Salt, Vol. 1, Salt Institute.

Lingle, R., Stanford, K. L., Peterson, P. E., and Woodhead, S. F. (1982) Wellbore Damage Zone Experimental Determination. Office of Nuclear Waste Isolation Report ONWI-349, Battelle Memorial Institute, Columbus, Ohio.

National Research Council (1985) Groundwater Contamination. Geophysics Study Committee, Geophysics Research Forum, Commission on Physical Sciences, Mathematics, and Resources, National Academy press, Washington, D. C.

Peach, C. J. (1991) Influences of Deformation on the Fluid Transport properties of Salt Rocks. Ph.D. Dissertation, University of Ultrecht, Ultrecht, The Netherlands, 238 p.

Peterson, E. W. (1987) Fluid Flow Measurements of test Series $A$ and $B$ of the Small-Scale Seal Performance Tests. Sandia National Laboratories Report SAND87-7041, Albuquerque, NM.

Pfeifle, T. W., Mellegard, K. D., and Senseny, P. E. (1983) Constitutive Properties of Salt from Four Sites. Office of 
Nuclear Waste Isolation Report ONWI-314, Battelle Memorial Institute, Columbus, Ohio.

Pfeifle, T. W. (1991) Consolidation, Permeability and Strength of Crushed Salt/Bentonite Mixtures With Application to the WIPP. Sandia National Laboratories Report SAND90-7009, Albuquerque, NM.

Senseny, P. E., Hansen, F. D., Russell, J. E., Carter, N. L., and Handin, J. W. (1992) Mechanical Behavior of Rock Salt: Phenomenology and Micromechanisms. International Journal of Rock Mechanics Mining Science \& Geomechanical Abstract, 29, pp. 363-378.

Shor, A. J., Baes, C.F., and Canonico, C. M. (1981) Consolidation and Permeability of Salt in Brine. Oak Ridge National Laboratory Report ORNL-5774, Oak Ridge, TN.

Sjaardema, G. D., and Krieg, R. D. (1987) A Constitutive Model For the Consolidation of WIPP Crushed Salt and Its Use in Analyses of Backfilled Shaft and Drift Configurations. Sandia National Laboratories Report SAND87-1977, Albuquerque, NM.

Stormont, J. C., and Daemen, J. J. K. (1992) Laboratory Study of Gas Permeability Changes in Rock Salt During Deformation. International Journal of Rock Mechanics Mining Science \& Geomechanical Abstract, 29, pp. 325-342.

Stormont, J. C., Howard, C. L., and Daemen, J. J. K. (1991) Changes in Rock Salt Permeability Due to Nearby Excavation. Proceedings of the 32nd U. S. Rock Mechanics Symposium, Norman, OK, pp. 899-907.

Sutherland, H. J., and Cave, S. P. (1980) ArgonGas Permeability of New Mexico Rock Salt Under Hydrostatic Compression. International
Journal of Rock Mechanics Mining Science \& Geomechanical Abstract, Vol. 17, pp. 281-288.

Torres, T. M., Howard, C. L., and Finley, R. E. (1992) Development, Implementation, and Early Results: Test Series D, Phase 1 of the SmallScale Seal Performance Tests. Sandia National Laboratories Report SAND91-2001, Albuquerque, NM.

USEPA (1987) Report to Congress on Management of wastes From Exploration, Development, and Production of Crude Oil, Natural Gas, and Geothermal Energy. US Environmental Protection Agency Report EPA/530-SW-88-003, December, 1987.

Wawersik, W. R., and Zeuch, D. H. (1986) Modeling and Mechanistic Interpretation of Creep of Rock Salt Below 200 (C.

Tectonophysics, 121, pp. 125-152.

Zeuch, D. H., and Holcomb, D. J. (1991) Experimental and Modeling Results for Consideration of Crushed Natural Rock Salt Under Varying Physical Conditions. Sandia National Laboratories Report SAND90-2509, Albuquerque, NM.

Zeuch, D. H. (1990) Isostatic Hot-Pressing Mechanism Maps for Pure and Natural Sodium Chloride: Applications to Nuclear waste Isolation in Bedded and Domal Salt Formations. International Journal of Rock Mechanics Mining Science \& Geomechanical Abstract, Vol. 27, pp. 505-524.

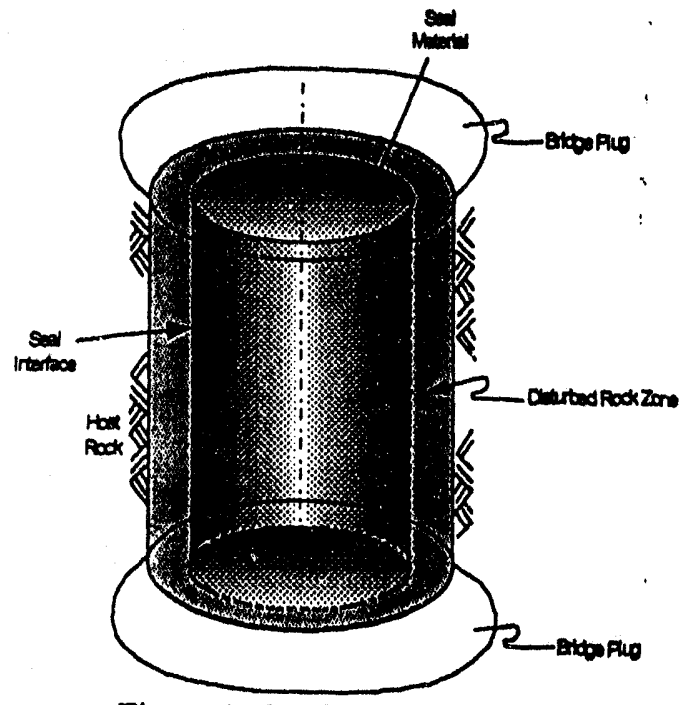

Figure 1. Typical seal system.

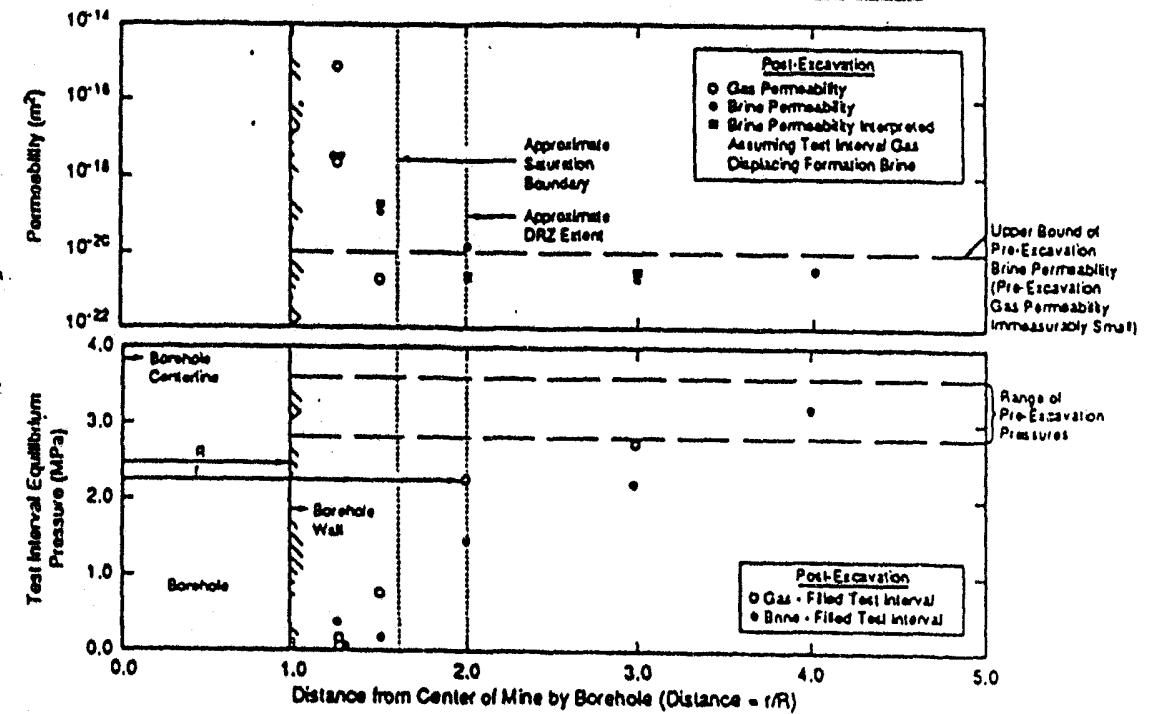

Figure 2. Permeability and test interval pressure as a function of distance from borehole (from Stormont et al., 1991). 


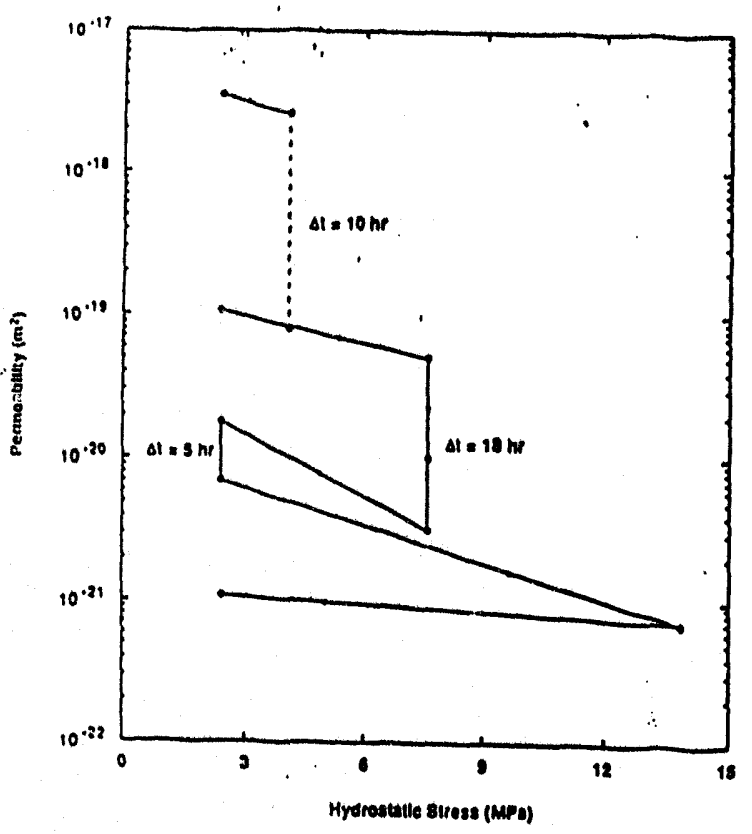

Figure 3. Permeability vs. hydrostatic stress data on rock salt cores (from Stormont and Daemen, 1992). .

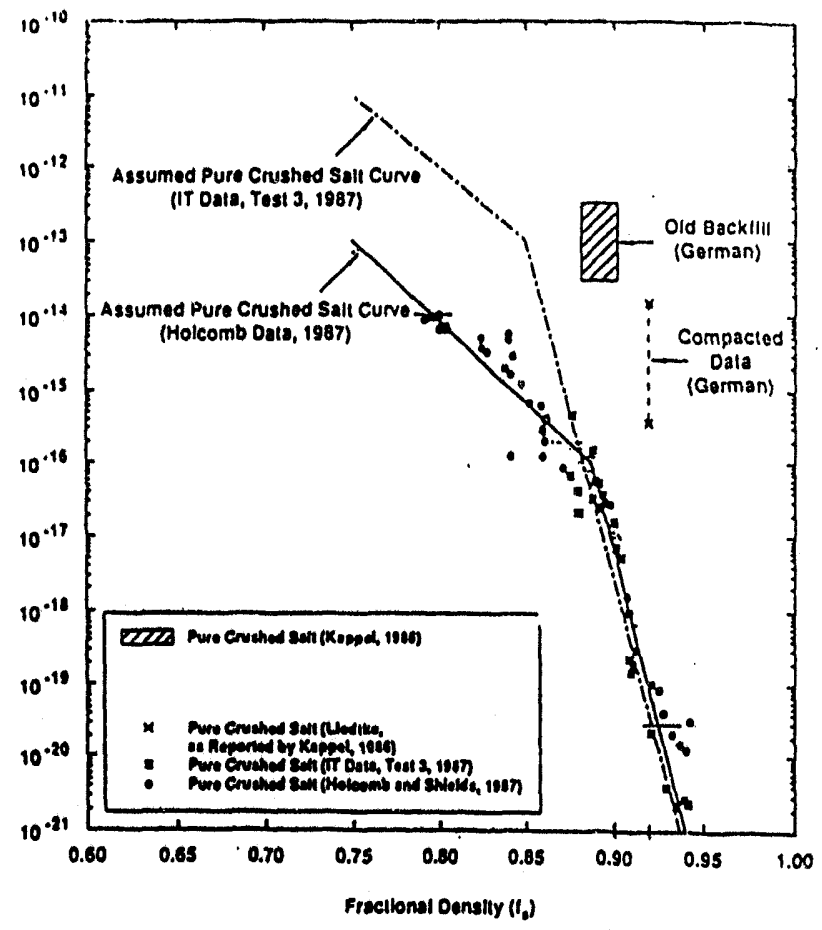

Figure 4. Granular salt permeability as a function of fractional density (from Butcher, 1991).

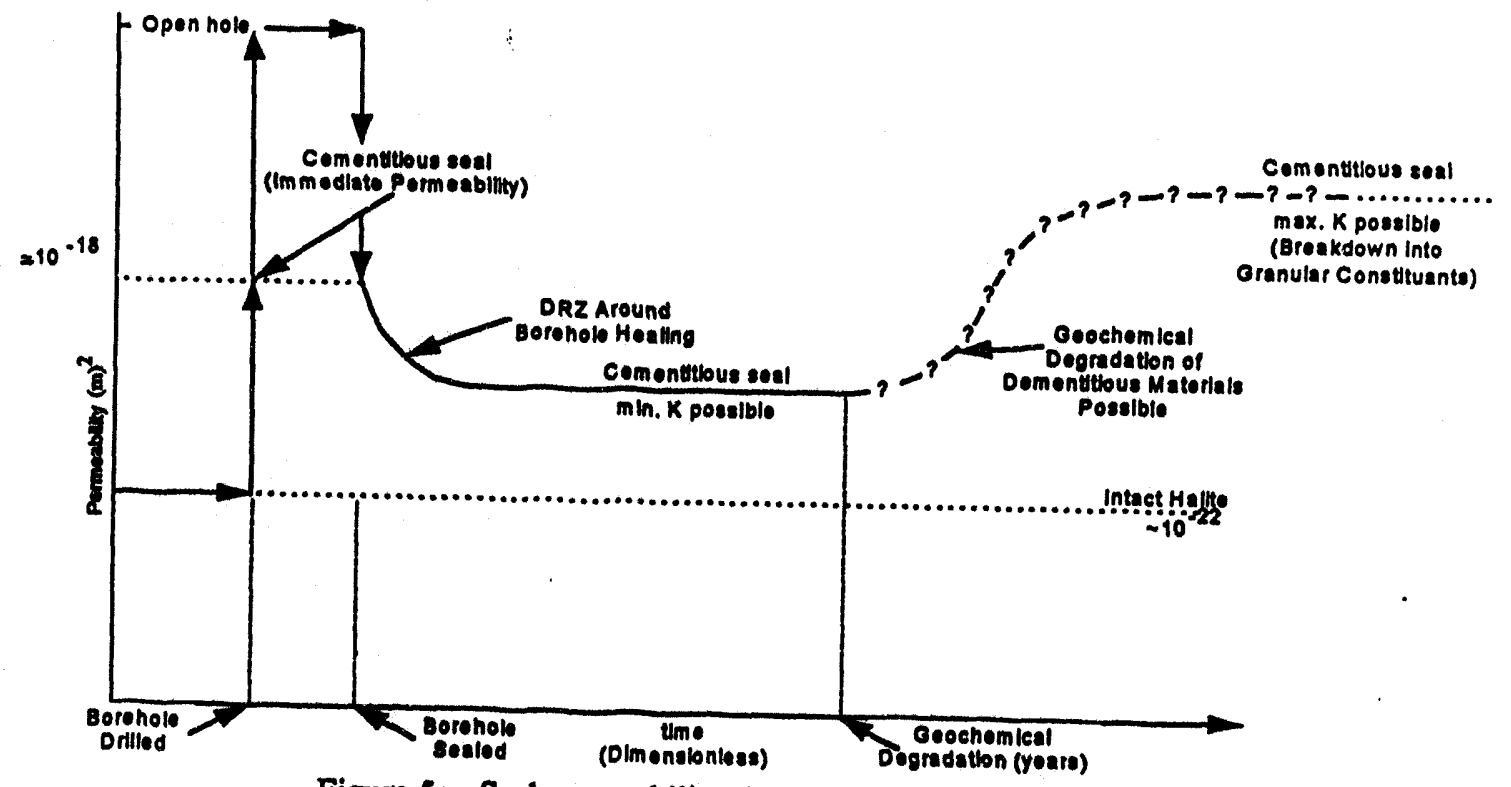

Figure 5a. Seal permeability-time curve - cementitious seals.

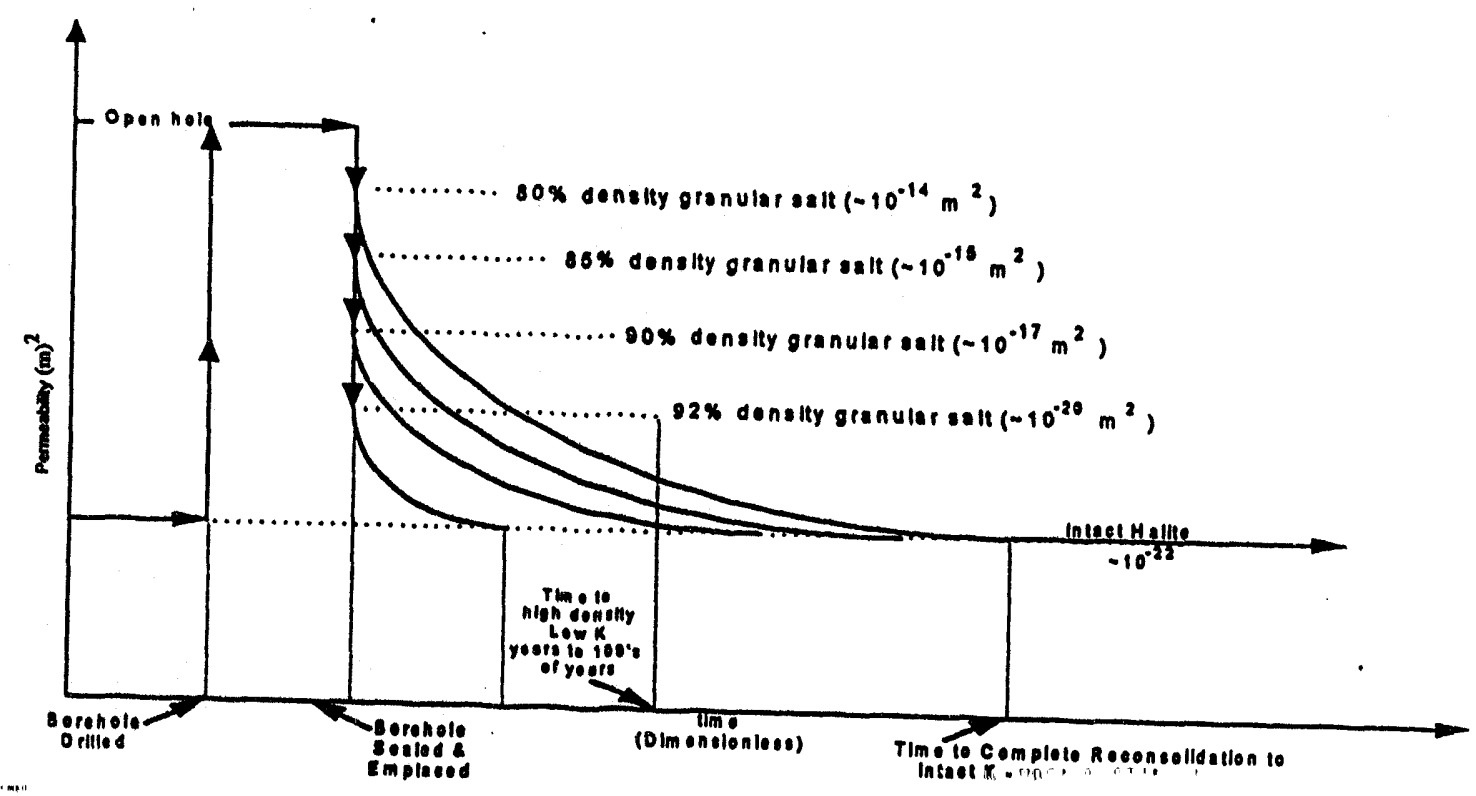



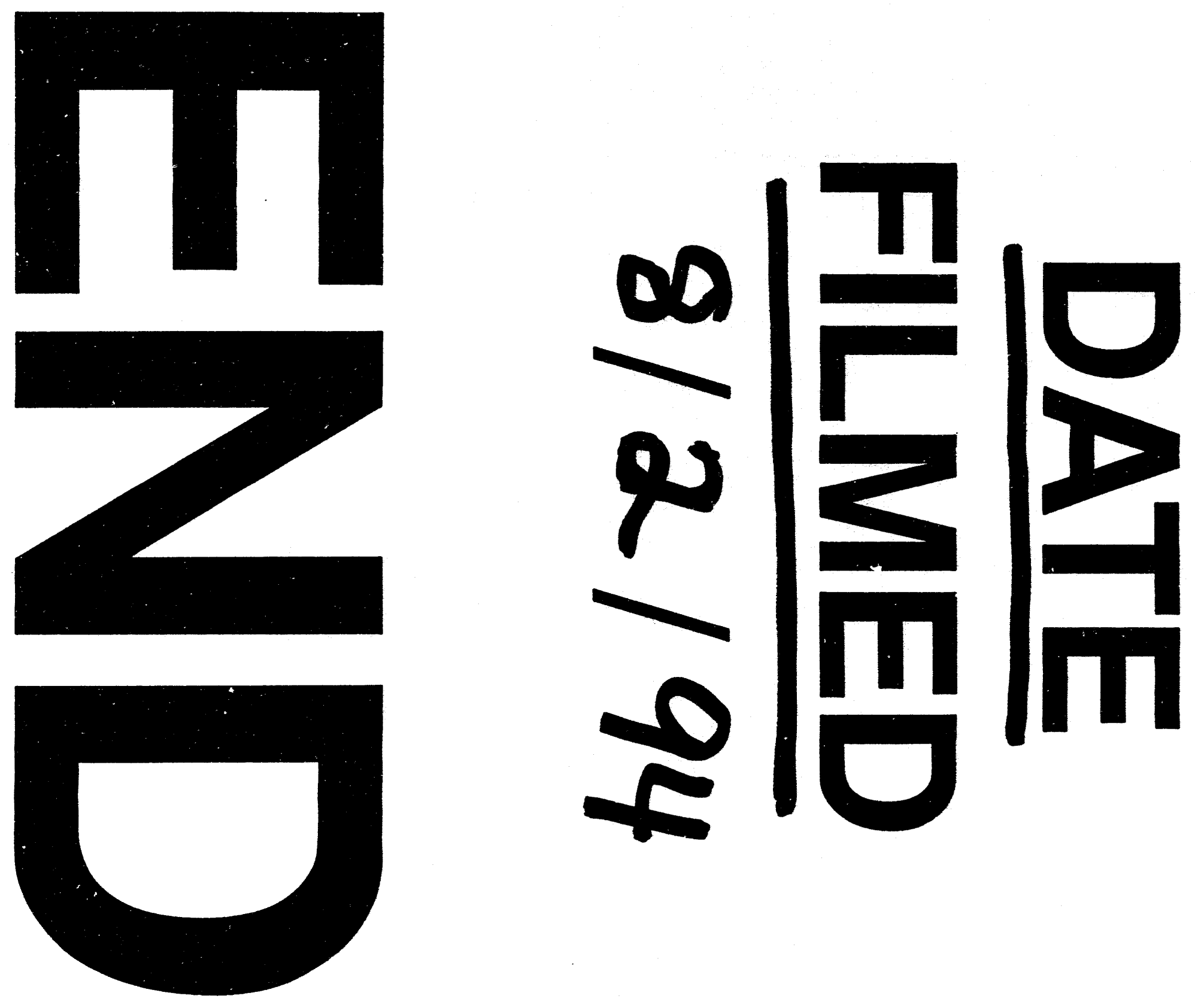